\title{
Author Correction: Emerging importance of satellite glia in nervous system function and dysfunction
}

\section{Menachem Hanani(1) and David C. Spray (1)}

Nature Reviews Neuroscience (2020) https://doi.org/10.1038/s41583-020-0333-z Published online 22 July 2020

The originally published article cited Fig. $2 \mathrm{~b}$ as being adapted with permission from ref. 78 . The text should have read "Part $b$ adapted with permission from ref. 66, Cambridge University Press". This has been corrected in the HTML and PDF versions of the manuscript.

https://doi.org/10.1038/s41583-020-00402-y I Published online 22 October 2020

(c) Springer Nature Limited 2020 